Available online at www.eccomasproceedia.org Eccomas Proceedia COMPDYN (2021) 2557-2572

ECCOMAS

\section{Proceedia}

COMPDYN 2021

$8^{\text {th }}$ ECCOMAS Thematic Conference on Computational Methods in Structural Dynamics and Earthquake Engineering

M. Papadrakakis, M. Fragiadakis (eds.) Streamed from Athens, Greece, 28 - 30 June 2021

\title{
ACCURATE COLLAPSE CAPACITY QUANTIFICATION FOR INFILLED RC FRAME BUILDINGS
}

\author{
Al Mouayed Bellah Nafeh ${ }^{1}$, Gerard J. O'Reilly ${ }^{1}$ \\ ${ }^{1}$ Centre for Training and Research on Reduction of Seismic Risk (ROSE Centre), Scuola \\ Universitaria Superiore IUSS Pavia \\ Palazzo del Broletto, Piazza della Vittoria 15, Pavia 27100, Italy \\ e-mail: \{mouayed.nafeh,gerard.oreilly\}@iusspavia.it
}

\begin{abstract}
The seismic assessment of reinforced concrete $(R C)$ structures with masonry infills is an important issue in modern earthquake engineering. This typology is prevalent in the southernMediterranean region and represents a large percentage of the Italian building stock. A pertinent aspect in their seismic assessment entails the quantification of structural performance up to global collapse. Collapse capacity can be quantified through a fragility function, which relates the probability of collapse to seismic intensity and is typically generated through computationally expensive non-linear dynamic analyses. However, simplified methodologies exist, offering a trade-off between accuracy and extensive analyses through empirical relationships derived from large analyses databases, and are typically referred to as $R-\mu-T$ relationships. To this end, this paper explores a simplified methodology for collapse assessment of infilled $R C$ frames using such $R$ - $\mu$-T relationships, incorporating the general response of the structural typology and employing average spectral acceleration AvgSa as a more accurate and appropriate intensity measure (IM). Such an approach can be of great assistance to practitioners, stakeholders and decision-makers in quantifying the collapse capacity of structures, as it removes the need for large computational analysis whilst still maintaining a high level of accuracy. This paper illustrates the robustness of the developed $R-\mu-T$ relationships for infilled $R C$ frames in quantifying median collapse intensities and dispersions and compares the outcome with traditional non-linear dynamic analyses for several archetypical 3D buildings, representative of the aforementioned typology found in Italy.
\end{abstract}

Keywords: infilled; assessment; collapse quantification; average spectral acceleration; performance-based. 


\section{INTRODUCTION}

Italian and European reinforced concrete (RC) frame buildings with masonry infill panels comprise a significant portion of the Mediterranean building stock (Figure 1). Before the 1970s (i.e. before the introduction of suitable seismic provisions), buildings in Italy in specific, and also across Southern Europe, were generally designed and constructed to resist gravity loads only [1,2]. In Italy, these were designed according to Regio Decreto (RD2229/1939) [3]. This design approach entails the use of the allowable stress method for the detailing of structural sections. Structural elements designed this way were typically characterised with inadequate seismic detailing. For example, the use of smooth rebars, low compressive strengths for concrete, and no consideration for a ductile failure mechanism (i.e. capacity design, strong column-weak beam formulation). Furthermore, unreinforced clay brick masonry infills were typically used as partitioning and façade elements based on their thermal and acoustic insulation, fire retarding and moisture control behaviour. These elements, however, were not considered in the structural design and therefore their effects on the structural response were neglected. Experimental and analytical studies, however, have outlined the effects of masonry infills on the global lateral response of the structural system [4-11]. These effects are characterised by a significant addition in lateral stiffness and a sudden drop in lateral strength with the rupture of infills on one or several storeys.

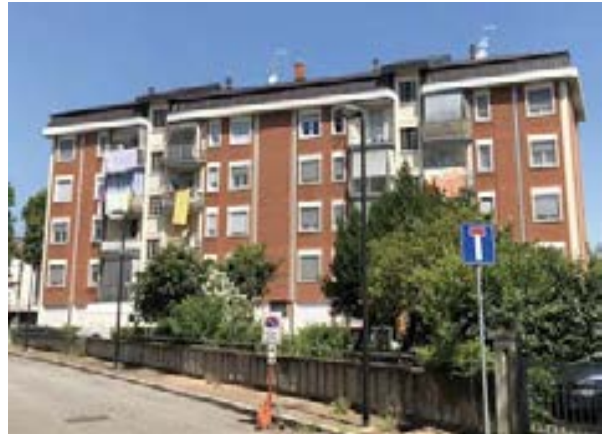

(a)

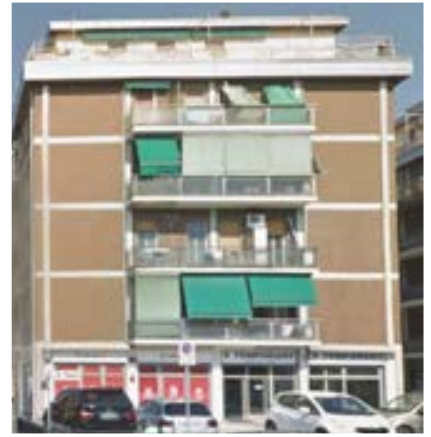

(b)

Figure 1: Typical Italian residential housing using infilled frame structures

Moreover, assessing the structural performance of structures requires accurate quantification of the exceedance of any structural demand-based performance level. The latter is typically quantified using fragility curves, which link the probability of exceeding predefined thresholds of demand for a given intensity level of ground-shaking. These are usually the end-result of extensive numerical analysis (i.e. numerical modelling, ground-motion selection, nonlinear dynamic analyses). To reduce the computational effort and time required by such analyses, simplified tools and methodologies for the assessment of RC frame structures have emerged, with the introduction of the SPO2IDA [12], SPO2FRAG [13] and other simplified methodologies [14-16]. These simplified approaches utilise $R-\mu-T$ for a direct estimation of the seismic demand and capacity. The aim of these tools is to supply users with aid in the quantification and mitigation of seismic risk compatible with different guidelines [17,18]. For example, the inclusion of SPO2IDA within the FEMA P-58 guidelines [19] can be considered a testimony to the added value of simplified tools in performance-based earthquake engineering (PBEE) [20]. To this end, the aim of the study is to present and further develop a simplified methodology previously introduced as ExtendedSPO2IDA [21], which had been tailored specifically for infilled RC frame structures. Previously, the $R-\mu-T$ relationships used in this tool were fitted considering the $5 \%$ damped spectral acceleration at the fundamental period, 
$\operatorname{Sa}\left(T_{1}\right)$. Therefore, subsequent sections will revisit the issue of a suitable IM choice for the characterisation of seismic demand in infilled RC frames. Subsequently, a refitting of the aforementioned tool is then conducted with reference to the selected IM. Two case study buildings are then presented to verify and evaluate the refitted tool in terms of median collapse intensities in comparison with results obtained from a non-linear dynamic analysis with a rigorous ground-motion selection and fully detailed numerical models.

\section{SUITABLE CHOICE OF INTENSITY MEASURE}

Average spectral acceleration ( $\mathrm{AvgSa}$ ) has been observed in several studies [22-24] to be a more advantageous intensity measure (IM) when compared to spectral acceleration at the fundamental period $\left(S a\left(T_{1}\right)\right)$ and particularly for the quantification of the collapse intensity for RC frames [25-27]. Efficiency and sufficiency are often the metrics used when comparing IMs. The former represents the capability of a selected IM to accurately predict a designated EDP, while the latter examines the level of independence of the structural response value from seismological properties (e.g. magnitude, rupture distance).

The definition of $A v g S a$ thus incorporates spectral acceleration intensities at periods around $T_{1}$, which can consider the elongation effects of a structural system up to collapse and also the higher mode contributions at periods shorter than $T_{1}$. This definition has rendered it a better predictor in terms of reduced dispersion (i.e. increased efficiency) when large deformations and non-linearities start occurring in the structural model. This comparison is highlighted in Figure 2 , in terms of incremental dynamic analysis (IDA) results on two single-degree-of-freedom (SDOF) systems studied previously in Nafeh et al. [21]. IDA is conducted using the FEMA P695 [28] far-field record set and is presented in terms of the median, $16^{\text {th }}$ and $84^{\text {th }}$ percentiles with $S a\left(T_{1}\right)$ and $A v g S a$ as IMs. From these IDA results, one can notice a noticeable change in the dispersion of the results reflected in the quantiles at each intensity measure level. IDA curves for two SDOF systems are presented herein in Figure 2. It can be observed that for both cases, when employing $A v g S a$, the dispersion at collapse decreased by $46.9 \%\left(\beta_{\mathrm{IM}=S a(\mathrm{~T} 1)}=0.35\right.$, $\left.\beta_{\mathrm{IM}=A v g S a}=0.18\right)$ and $41.5 \%\left(\beta_{\mathrm{IM}=S a(\mathrm{~T} 1)}=0.34, \beta_{\mathrm{IM}=A v g S a}=0.20\right)$ as opposed to using $S a\left(\mathrm{~T}_{1}\right)$ for the two respective cases.

Eads et al. [25] noted relatively stable collapse risk estimates across various ground motions sets for steel MRFs and shear wall structures when employing AvgSa. O'Reilly [29] infers similar conclusions on the beneficial use of $A v g S a$ and the limitations of $S a\left(T_{1}\right)$ in the collapse assessment of non-ductile infilled RC frames, of interest to this study. Following the above remarks, $A v g S a$ has been seen to be an advantageous IM for assessing the collapse capacity of infilled RC frames and will be explored herein for the development of simplified collapse assessment tools. 

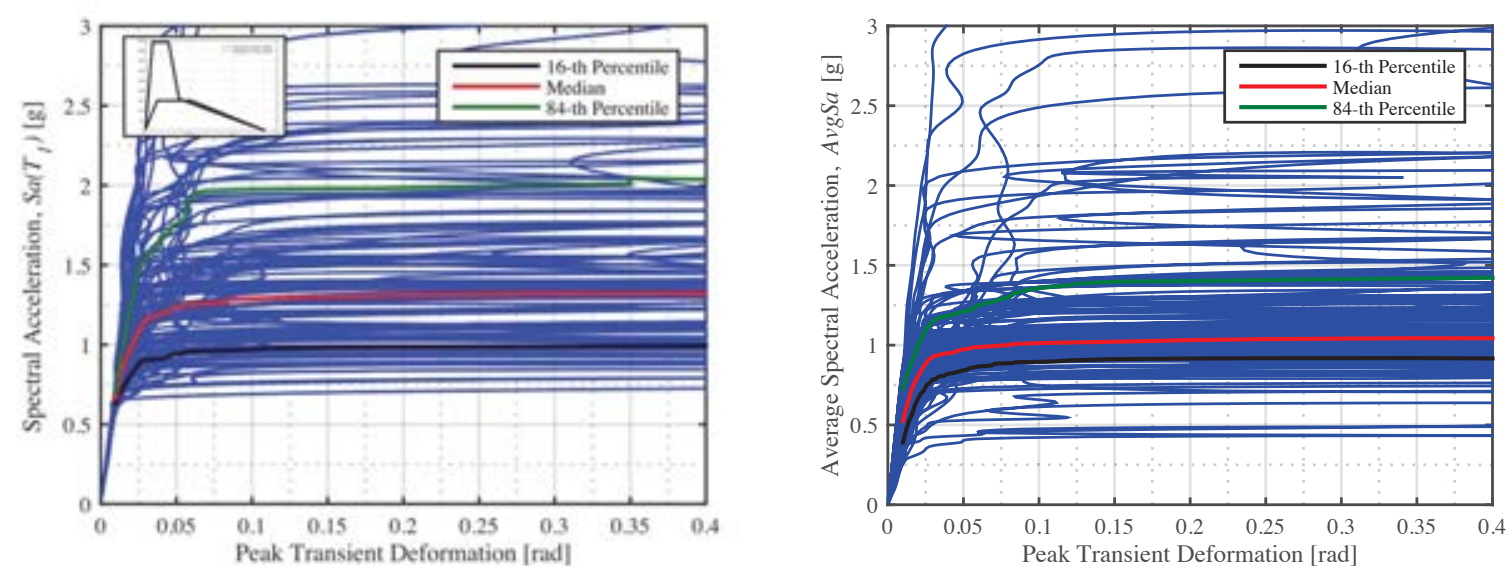

(a)
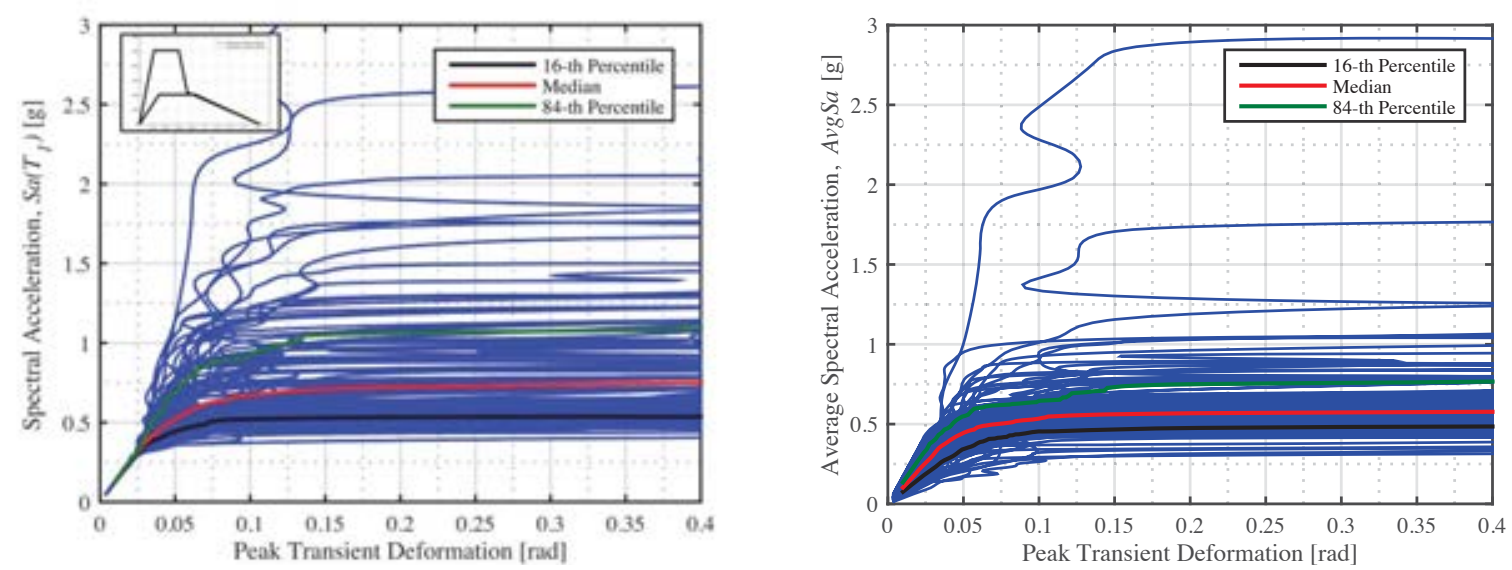

(b)

Figure 2. Comparison of IDA quantiles (16th, 50th and 84th) for two SDOF systems (a-b) considering AvgSa (left) and $\mathrm{Sa}\left(T_{1}\right)$ (right) as IMs using FEMA P695 Far-Field record set

\section{DEVELOPMENT OF A SIMPLIFIED TOOL FOR COLLAPSE ASSESSMENT}

The fundamental concept behind the development [12] and extension [21] of the SPO2IDA tool is to relate the force-deformation capacity of a given frame structure (obtained through non-linear static, or static pushover (SPO), analysis) to its dynamic counterpart, typically illustrated using IDA [30]. The extension of SPO2IDA was developed to incorporate the behaviour of infilled RC frames whose behaviour was not properly represented in the original version. This behaviour is characterised by a significant addition in lateral stiffness followed by a sudden loss of lateral strength capacity due to the localisation of damage on one or several storeys (i.e. formation of a soft-storey mechanism due to the sudden rupture of infill panels) shown in Figure 3. 


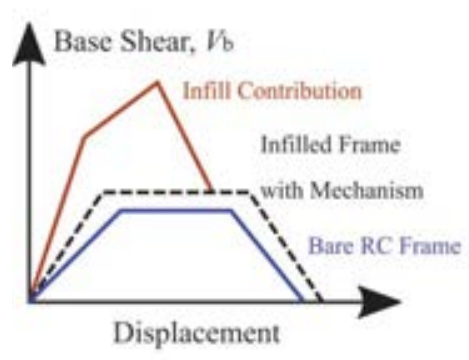

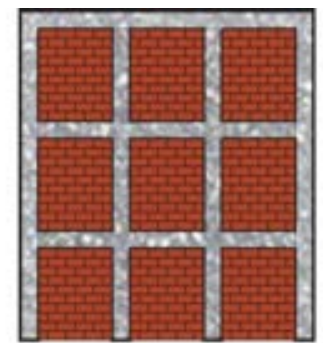

Infilled RC Frame

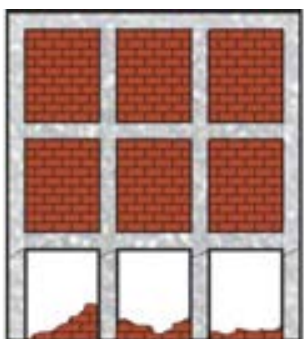

Infilled RC Frame with Mechanism

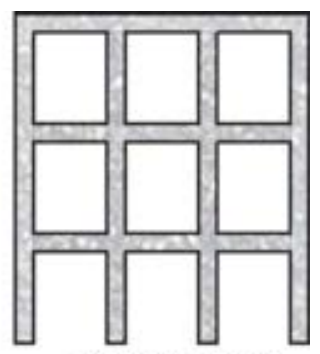

Bare RC Frame

Figure 3: Illustration of the contribution of infill panels on the stiffness and strength of the global system before period elongation due to the formation of a non-ductile mechanism.

For the development of the tool, a large dataset of SDOF systems with varying backbone parameters is required. IDA then subjects the set of SDOF systems to increasing levels of intensity until numerical collapse is achieved. This forms a library of seismic demand-capacity models for various SDOF with distinct features. The library can then be utilised for a direct estimation of the seismic demand and capacity through interpolation and fitted closed-form expressions. This is done using results from SPO and eigenvalue (modal) analyses to relate a multi-degree-of-freedom (MDOF) system to an SDOF oscillator (presented in Figure 4). Then, the median collapse intensity and dispersion associated with the collapsing intensity are estimated using the results of the extensive numerical analysis (i.e. IDAs) and a set of $R-\mu-T$ relationships relating the SPO backbone characteristics with the medians and dispersions obtained.

The two ground motion record sets from INNOSEIS [31] that are representative of European seismicity (i.e. medium and high seismicity) were utilised for the IDA related to this study. Subsequent sections will highlight the methodology proposed in this study, which incorporates the use of SDOF systems representative of the response of infilled RC typology, quantifying the dynamic response through IDA and fitting closed-form expression at each response branch up to global collapse.

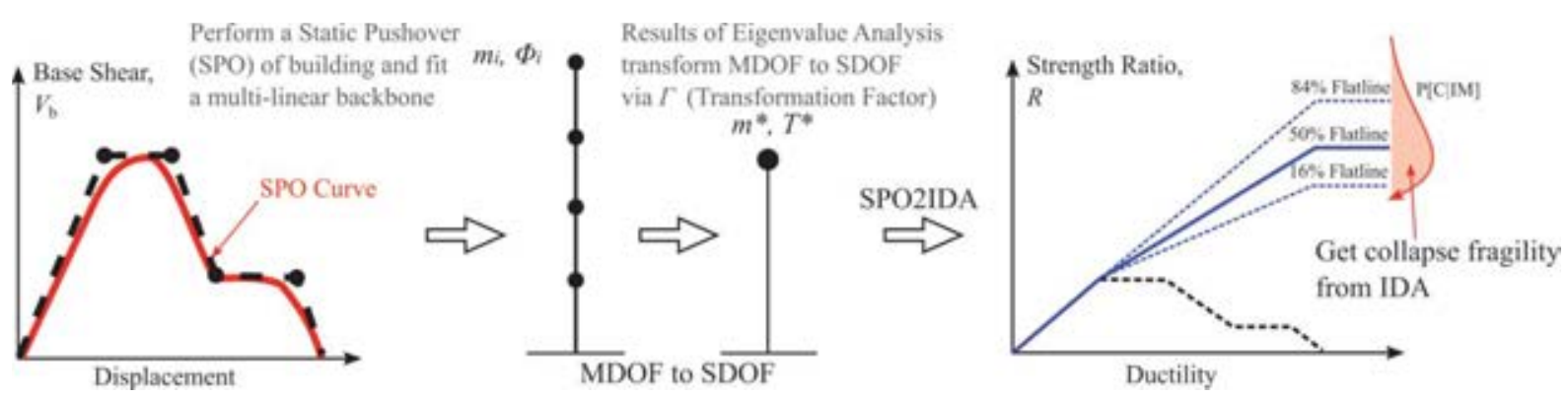

Figure 4: Direct estimation of seismic demand-capacity of a multi-degree-of-freedom system using single-degree-of-freedom systems through extendedSPO2IDA via results of pushover and eigenvalue analysis.

\subsection{Methodology}

This section introduces the methodology employed for analysing a set of equivalent SDOF oscillators to analyse the dynamic capacity properties of infilled RC frames. The methodology is as follows:

1) Perform IDAs on SDOFs whose capacity curve parameters are known a priori (from a previously generated set accounting for the variability in the backbone parameters) to relate the IM (i.e. $A v g S a$ ) to the engineering demand parameter (EDP) of the system. 
2) Find the static response parameters corresponding to each SDOF analysis $\left(R_{s t, i}, \mu_{\mathrm{st}, \mathrm{i}}\right)$ defined in Equations 1.1 and 1.2, where $i$ corresponds to the response branch (i.e. elastic, post-capping, softening, residual strength (plateau) and strength degradation), $V_{b, s t, i}$ and $V_{b, y}$ are respectively the base shear values at the response branch and the nominal yield force, $\Delta_{r, s t, i}$ and $\Delta_{r, y}$ are respectively the roof displacement values at the response branch and displacement corresponding to the nominal yield force.

$$
\begin{aligned}
& R_{s t, i}=V_{b, s t, i} / V_{b, y} \\
& \mu_{s t, i}=\Delta_{r, s t, i} / \Delta_{r, y}
\end{aligned}
$$

Equation 1.2

3) Process the IDA results and convert the median and fractile quantities (i.e. $16^{\text {th }}$ and $84^{\text {th }}$ percentiles) IM-EDP IDA curves to the corresponding dynamic response parameters $\left(R_{d y n, i}, \mu_{\text {dyn,i }}\right)$ defined in Equations 2.1 and 2.2. $S a_{y}$ is the yield spectral acceleration, $\Gamma$ is the transformation factor obtained from eigenvalue analysis. $T^{*}, m^{*}$ , $\Delta_{y}^{*}$ and $V_{y}{ }^{*}$ are respectively the period, effective mass, deformation capacity at yield and the nominal yielding force of the SDOF system. $S a_{\text {ratio }}$ is the ratio of the spectral shape introduced by Eads et al. [26]. The steps presented herein were only performed during the processing of the IDAs and will not be later required by the user as input.

$$
\begin{aligned}
& R_{d y n, i}=\frac{S a\left(T^{*}\right)_{i}}{S a_{y}} \\
& \mu_{d y n, i}=\frac{\Delta_{d y n, i}}{\Delta_{d y n, y}} \\
& S a_{\text {ratio }}=\frac{S a\left(T^{*}\right)}{\operatorname{AvgSa}\left(T^{*}[a, b]\right)}
\end{aligned}
$$

Equation 2.1

Equation 2.2

Equation 2.3

From Equations 2.1 and 2.3:

$$
\begin{gathered}
S a_{\text {ratio }} \operatorname{AvgSa}\left(T^{*}[a, b]\right)=\operatorname{Sa}\left(T^{*}\right)=R_{d y n, i} S a_{y} \\
\frac{\operatorname{AvgSa}\left(T^{*}[a, b]\right)}{\operatorname{Say}}=\frac{R_{d y n, i}}{S a_{\text {ratio }}}=\rho \\
A v g S a=\rho S a_{y} \Gamma
\end{gathered}
$$

where the transformation factor is introduced in Equation 2.6 to estimate the AvgSa for the MDOF system. It is also noted that:

$$
\begin{aligned}
S a_{y} & =\frac{4 \pi^{2} * \Delta_{y}^{*}}{T^{* 2}}=\frac{V_{y}}{m^{*}} \\
T^{*} & =2 \pi \sqrt{\frac{m^{*} * \Delta_{y}^{*}}{V_{y}^{*}}}
\end{aligned}
$$

4) Interpolate the dynamic response parameters $\left(R_{d y n, i}, \mu_{\mathrm{dyn}, \mathrm{i}}\right)$ corresponding to the former (as highlighted in Figure 5) for each static response branch of every SDOF system. The step herein populates a database of static vs dynamic response parameters which will be further utilised to fit the expressions in Table 1 via two-step regression analysis. 
a) $1^{\text {st }}$ step: obtain a functional form expressing the median and fractile quantities (i.e. $\left.R_{d y n, i}, \mu_{\mathrm{dyn}, \mathrm{i}}\right)$ of the IDA in function of the static parameters $\left(R_{s t, i}, \mu_{\mathrm{st}, \mathrm{i}}\right)$ obtained from static pushover analyses.

b) $2^{\text {nd }}$ step: relate the functional form coefficients in step (a) to the fundamental period and other relevant capacity parameters.

\subsection{Fitting of Functions}

For the two-step regression analysis conducted herein, the Least Absolute Residuals (LAR) and the Bisquare weights methods were employed to increase the robustness of the fitting routine. The LAR method finds a curve that minimises the absolute difference of the residuals, rather than the squared differences. Therefore, extreme values have a lesser influence on the fit. The Bisquare weights method minimises a weighted sum of squares, where the weight given to each data point depends on how far the point is from the fitted line. Points near the line get full weight and points farther from the line get reduced weight. The LAR method has been used herein.

The resulting $R-\mu-T$ relationships from two-step regression analysis are presented in Table 1, whereas Figure 5 illustrates the strength and ductility factors figuring in the Equations for each response branch. A simple linear functional form is attributed to the relationship between the dynamic strength factors and the ductilities at each response branch threshold. A more complex functional form is used for the introduction of the fundamental period, reduction in strength due to the rupture of infills, and the corresponding residual strength capacity of the structure (i.e. as seen in the $2^{\text {nd }}$ step regression). Previous work in Nafeh et al. [21] opted for the use of more complex functional forms to characterise the relationship between the static and dynamic response parameters presented in the previous section. Moreover, the reduction in strength and residual capacity of the global system was not incorporated in past work.

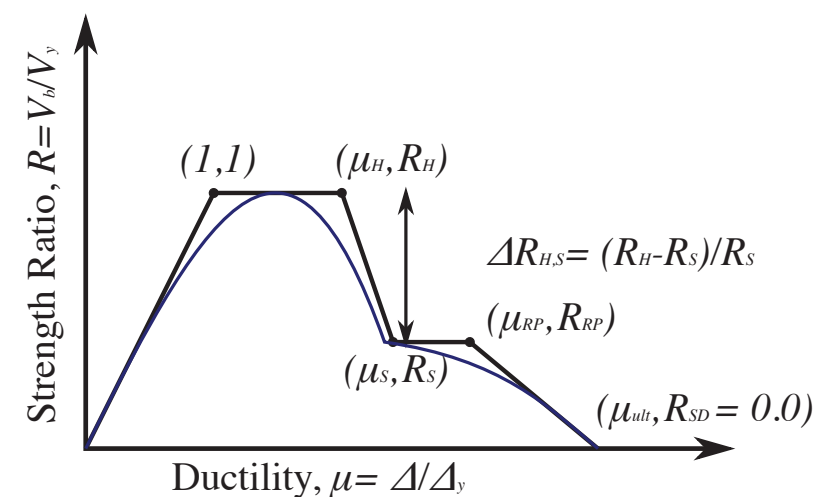

Figure 5: Illustration of the normalized static pushover curve and the response branch parameters noted in the Equations in Table 1 
Table 1: Closed-form expression denoting $R-\mu$ - $T$ relationships for infilled $\mathrm{RC}$ frames for each response branch using two-step regression analysis and implemented in extendedSPO2IDA

\begin{tabular}{|c|c|c|}
\hline Response Branch & $1^{\text {st }}$ Step Regression & $2^{\text {nd }}$ Step Regression \\
\hline Hardening $(H)$ & $\begin{array}{c}R_{d y n, H}=\alpha_{1, q t} \mu_{H}+\beta_{1, q t} \\
\text { Where } \mu_{H} \in\left(1 ; \mu_{H}\right]\end{array}$ & $\begin{array}{c}\alpha_{1,16}=-0.5563 T^{* 2}+0.711 T^{*}+0.0115 \\
\beta_{1,16}=0.5563 T^{* 2}-0.711 T^{*}+0.9885 \\
\alpha_{1,50}=-0.634 T^{* 2}+0.9239 T^{*}+0.08742 \\
\beta_{1,50}=0.634 T^{* 2}-0.9239 T^{*}+0.9126 \\
\alpha_{1,84}=-1.053 T^{* 2}+1.509 T^{*}+0.1239 \\
\beta_{1,84}=1.053 T^{* 2}-1.509 T^{*}+0.8761\end{array}$ \\
\hline Softening $(S)$ & $\begin{array}{c}R_{d y n, S}=\alpha_{2, q t} \mu_{s}+\beta_{2, q t} \\
\text { Where } \mu_{S} \in\left(\mu_{H} ; \mu_{S}\right]\end{array}$ & $\begin{aligned} \alpha_{2,16} & =0.2186\left(\frac{T^{*}}{\Delta R_{H, S}}\right)^{0.34} \\
\beta_{2, q t}= & 0.7782\left(\frac{T^{*}}{\Delta R_{H, S}}\right)^{-0.08327} \\
\alpha_{2,50} & =0.377\left(\frac{T^{*}}{\Delta R_{H, S}}\right)^{0.2951} \\
\beta_{2,50} & =0.6189\left(\frac{T^{*}}{\Delta R_{H, S}}\right)^{-0.1445} \\
\alpha_{2,84} & =0.5857\left(\frac{T^{*}}{\Delta R_{H, S}}\right)^{0.2825} \\
\beta_{2,84} & =0.4087\left(\frac{T^{*}}{\Delta R_{H, S}}\right)^{-0.3045}\end{aligned}$ \\
\hline Residual Plateau $(R P)$ & $\begin{array}{c}R_{d y n, R P}=\alpha_{3, q t} \mu_{R P}+\beta_{3, q t} \\
\text { Where } \mu_{R P} \in\left(\mu_{S} ; \mu_{R P}\right]\end{array}$ & $\begin{array}{c}\alpha_{3,16}=0.07401 T^{* 2}+0.04584 T^{*}-0.00548 \\
\beta_{3,16}=-2.158 R_{R P}^{2}+2.196 R_{R P}+0.9244 \\
\alpha_{3,50}=0.04537 T^{* 2}+0.08579 T^{*}-0.01045 \\
\beta_{3,50}=-1.549 R_{R P}^{2}+1.754 R_{R P}+1.288 \\
\alpha_{3,84}=0.06217 T^{* 2}+0.2534 T^{*}-0.0286 \\
\beta_{3,84}=-2.174 R_{R P}^{2}+2.179 R_{R P}+1.552\end{array}$ \\
\hline $\begin{array}{l}\text { Strength Degradation } \\
\qquad(S D)\end{array}$ & $R_{d y n, S D}=\alpha_{4, q t} \mu_{S D}+\beta_{4, q t}$ & $\begin{array}{c}\alpha_{4,16}=0.01552 T^{*}-0.001861 \\
\beta_{4,16}=-1.662 T^{* 2}+2.049 T^{*}+1.173 \\
\alpha_{4,50}=0.02035 T^{*}-0.002569 \\
\beta_{4,50}=-2.008 T^{* 2}+2.541 T^{*}+1.405 \\
\alpha_{4,84}=0.02875 T^{*}-0.003179 \\
\beta_{4,84}=-3.886 T^{* 2}+4.641 T^{*}+1.553\end{array}$ \\
\hline
\end{tabular}

\subsection{Verification of extendedSPO2IDA using SDOF validation set}

An additional set of 40 equivalent SDOFs was employed as a test set for the functions previously fitted. IDA was again carried out using the INNOSEIS record set. Subsequently, the median collapse intensity of the SDOF systems and their corresponding dispersions were extracted. Consequently, the verification of the developed tool refers to the comparison of the extracted values, obtained via traditional IDA and the values obtained from applying extendedSPO2IDA. The median intensity and associated dispersion for the collapsing cases are illustrated in Figure 6. The observations show a relatively good agreement when comparing the two analysis methods (i.e. extensive IDA and simplified SPO2IDA). Additionally, Figure 6 reports the comparison of the median collapse intensities and dispersions obtained using the original version of the extendedSPO2IDA tool (i.e. calibrated on the spectral acceleration at the fundamental period $S a\left(T_{1}\right)$ ). The comparison shows the capability of the original version in predicting the response of the system. However, the main difference and benefit of the AvgSabased tool are noted in the dispersion at collapse, where higher values for $\mathrm{IM}=\operatorname{Sa}\left(T_{1}\right)$ can be 
clearly seen when compared to $A v g S a$, indicating a reduction in uncertainty and increased efficiency and accuracy of the tool.

Further validation of the $R-\mu-T$ relationships is conducted on two case study structures by considering two distinct locations, where records differing from the INNOSEIS record set will be selected based on the seismicity of the said locations.

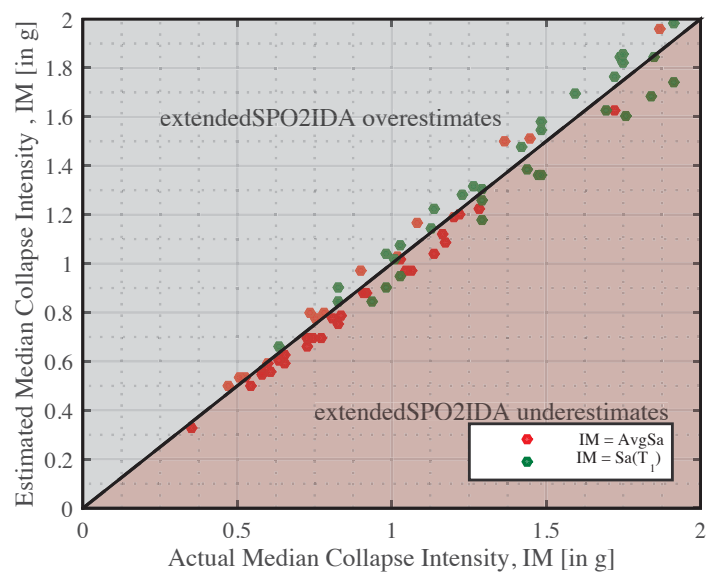

(a)

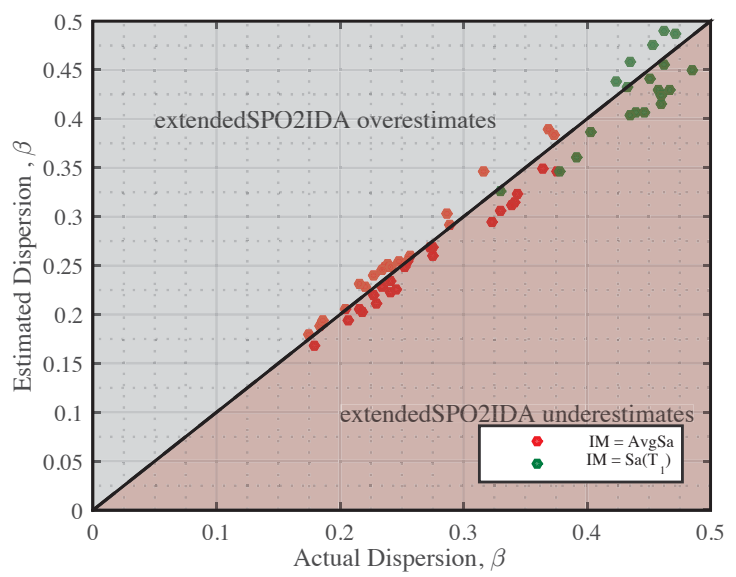

(b)

Figure 6. Comparison of the estimated (using extendedSPO2IDA) vs actual (using IDA) (a) median collapse intensity given in terms of $A v g S a$ and $S a\left(T_{1}\right)$ [in g] and (b) dispersion at collapsing runs considering an SDOF validation set.

\section{CHARACTERISATION AND NUMERICAL MODELLING OF CASE STUDY BUILDINGS}

The development of archetype numerical models characterising a particular building class forms the basis of structural performance quantification. To this end, population and housing statistics provide important information related to the prevalence of a structural typology as part of the regional building stock. Additional information concerning the architectural features of the built environment can be extracted from databases like ISTAT [32] to further characterise the building class.

Moreover, geographical specifications and conditions (i.e. building material, design methodology specific for a region, etc.) need to be accounted for. Generally, before the introduction of seismic provisions (i.e. before the 1970s), southern European RC residential buildings with masonry infills were designed to resist gravity loads only (termed GLD herein) with no consideration to ductile detailing. For the specific case of Italian structures, said buildings were designed to Regio Decreto 39 (RD2229/39) [3] with complementary references $[33,34]$. Design features include: frames span in one direction only, the use of smooth plain rebars and concrete with respectively low yield and compressive strengths; poor transverse detailing and shear reinforcement; inadequate detailing of the beam-column joints.

The two archetypes described herein form a subset of a larger database of RC buildings with masonry infill panels. They comprise two and six-storey structures with dimensioning of the span widths and space designations presented in Figure 7. The latter elements are representative of the Italian architectural definition at the construction period of interest. Applied permanent loads were defined as 500 and $450 \mathrm{~kg} / \mathrm{m}^{2}$ for typical floors and roofs respectively, whereas accidental loads of 200 and $150 \mathrm{~kg} / \mathrm{m}^{2}$ were applied. Allowable stresses equal to $5 \mathrm{~N} / \mathrm{mm}^{2}$ for concrete and $140 \mathrm{~N} / \mathrm{mm}^{2}$ for reinforcing steel were considered, as per RD2229/39. These values correspond to $29.2 \%$ and $33.3 \%$ of the maximum stresses for concrete and steel respectively. 
The corresponding sections and detailing found when conducting a simulated design for the two GLD archetype buildings are presented in Table 2.

The numerical modelling of the case study buildings was performed in OpenSees [35] using a 3D lumped-plasticity model. "forceBeamColumn" elements with a finite plastic hinge length were used to describe the structural response of beam-column elements. The latter elements are then coupled with zero-length elements at the plastic hinge locations utilising a "Pinching4" hysteretic material model based on the force-deformation relationships for non-conforming structures $[4,36]$. Interior and exterior beam-column joints with poor detailing and smooth bars with end-hooks were modelled using zero-length elements using a "Hysteretic" model elements to capture both flexural and axial behaviour accordingly with the recommendations of O'Reilly and Sullivan and De Risi et al. [4,37]. Rigid offsets were accounted for in the element transformation. Furthermore, the in-plane behaviour of masonry infill panels was modelled using the equivalent strut approach following the recommendations of Verderame et al. [36]. The difference in infill strength (weak, medium and strong) parameters used herein depends on the characterisation performed in Hak et al. [38]. Staircase elements were modelled similarly to the beam-column elements, accounting for the inclination through assigning adequate geometric transformations in both directions. Additionally, shear hinges were also implemented to account for the shear behaviour caused due to the short column effect typically observed in stairs elements. The architectural plan layouts and the corresponding numerical model of the case study buildings are presented in Figure 7. 

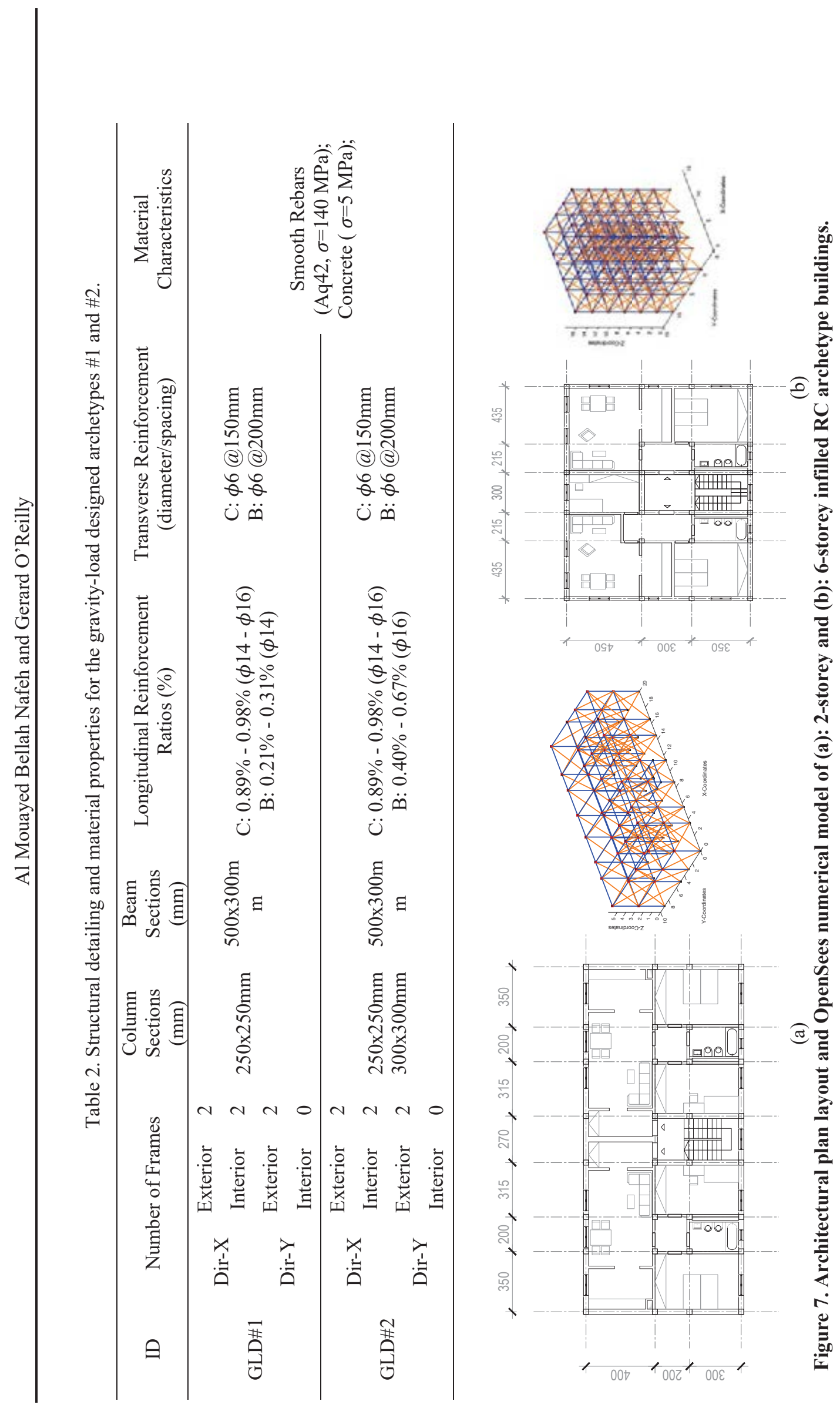


\section{APPLICATION OF EXTENDEDSPO2IDA}

Considering the application of extendedSPO2IDA, Monteleone di Spoleto and San Severo located in Central Italy were selected as case study locations for the archetypes GLD\#1 and GLD\#2, respectively, and correspond to high and medium seismicity. Subsequently, hazard analysis for record selection (as shown in Figure 8) was conducted using the OpenQuake engine [39] considering AvgSa as the IM and the site characteristics presented in Mori et al. [40]. The period range [ $\left.T_{\text {lower, }}, T_{\text {upper}}\right]$ was defined as outlined for non-ductile infilled RC frames in O'Reilly [29] with a spacing of $0.1 \mathrm{~s}$ and are shown in Table 3 . Records were then selected from the NGA database using the conditional mean spectrum method [41] with the modifications suggested by Kohrangi et al. [23] for AvgSa. The correlation model by Baker and Jayaram [42] was used in all cases and the geometric mean of the two components was used in the selection. Six intensity measure levels (IMLs) were investigated for the characterization of the structural response covering initial damage of the masonry infill panels up to global structural collapse.

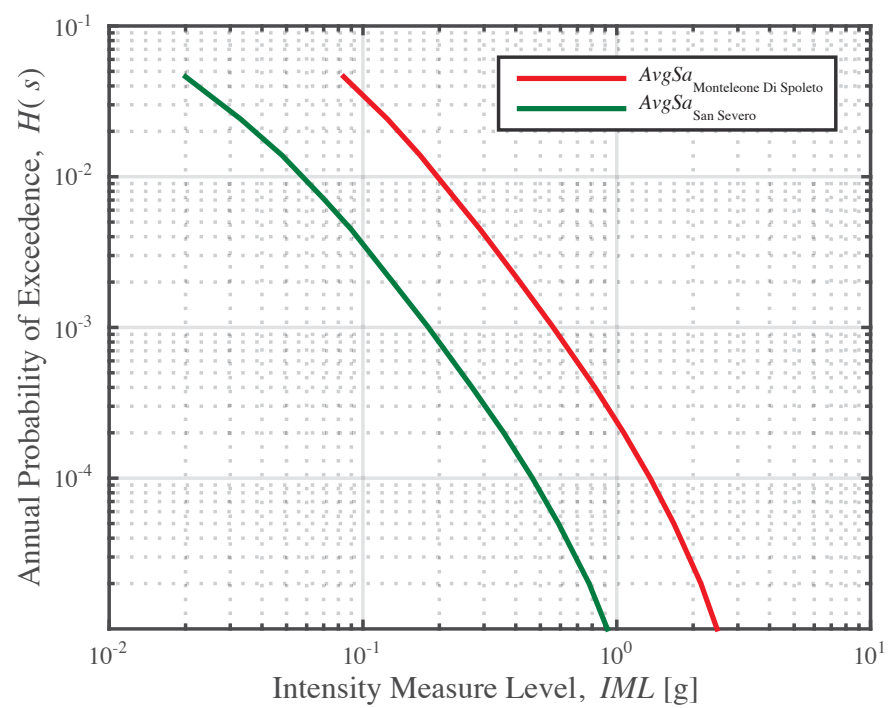

Figure 8: Hazard curves of Monteleone di Spoleto and San Severa highlighting the annual probability of exceedance of increasing intensity measure levels corresponding to $\mathrm{AvgSa}$

Table 3: Modal properties of the case study buildings

\begin{tabular}{|c|c|c|c|c|c|}
\hline \multirow{2}{*}{ ID } & \multirow{2}{*}{ Direction } & \multirow{2}{*}{ Period, $T$} & \multirow{2}{*}{ Modal Mass, $M$} & \multicolumn{2}{|c|}{ AvgSa } \\
\hline & & & & $T_{\text {lower }}$ & $T_{\text {upper }}$ \\
\hline \multirow{4}{*}{1} & $\mathrm{X}_{1}$ & $0.19 s$ & $81.6 \%$ & \multirow{4}{*}{$0.09 s$} & \multirow{4}{*}{$0.60 s$} \\
\hline & $Y_{1}$ & $0.21 s$ & $84.3 \%$ & & \\
\hline & $\mathrm{X}_{2}$ & $0.07 \mathrm{~s}$ & $11.5 \%$ & & \\
\hline & $\mathrm{Y}_{2}$ & $0.08 s$ & $10.6 \%$ & & \\
\hline \multirow{4}{*}{2} & $\mathrm{X}_{1}$ & $0.48 s$ & $82.0 \%$ & \multirow{4}{*}{$0.30 s$} & \multirow{4}{*}{$1.50 \mathrm{~s}$} \\
\hline & $\mathrm{Y}_{1}$ & $0.52 s$ & $83.4 \%$ & & \\
\hline & $\mathrm{X}_{2}$ & $0.16 s$ & $11.0 \%$ & & \\
\hline & $\mathrm{Y}_{2}$ & $0.35 s$ & $10.4 \%$ & & \\
\hline
\end{tabular}

First, a static pushover (SPO) analysis was conducted, where an inverse triangular load was applied laterally to the two principal directions of the case study structures. The results are presented in Figure 9(a), which when combined with the modal analysis output (i.e. the modal masses at each floor and the modal shape corresponding to the first-mode), can be used as input 
for the extendedSPO2IDA tool by considering the SPO analysis results in both directions and then linearizing the curves as suggested in Nafeh et al. [21] for the earlier versions of the tool. The median collapse intensity and dispersions are then directly extracted from the tool.

Second, a multiple stripe analysis (MSA) was conducted in OpenSees at increasing levels of intensity. The ground-motion pairs were applied simultaneously in both principal directions of the three-dimensional case study buildings. The results of the analysis in terms of $A v g S a$ and maximum peak storey drift $\theta_{\max }$ are illustrated in Figure 9(b). The median collapse intensity and dispersion due to the record-to-record variability were obtained using the maximum likelihood method. The collapse fragility curves obtained from MSA and extendedSPO2IDA are illustrated and compared in Figure 10.

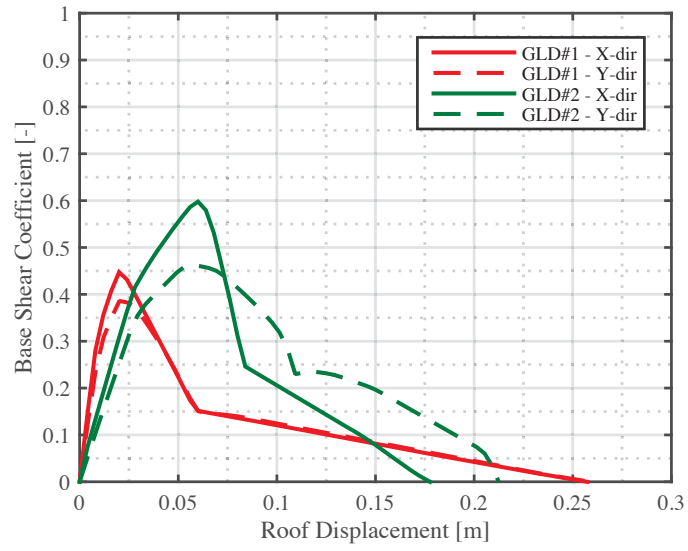

(a)

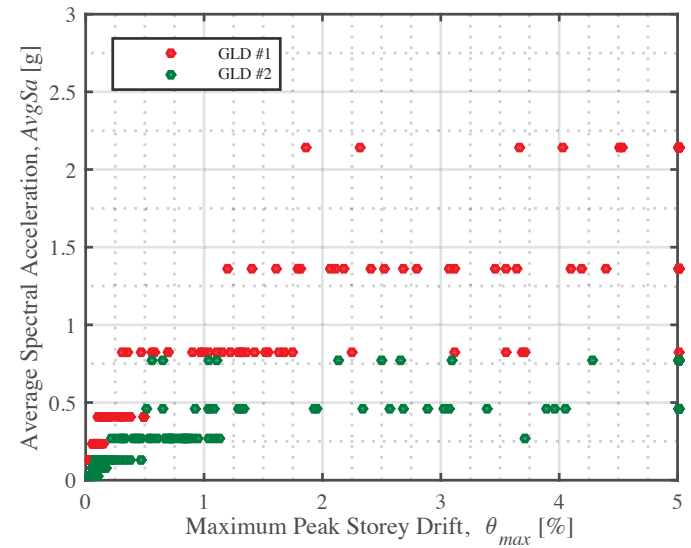

(b)

Figure 9: (a) Static pushover analysis curves for GLD\#1 and \#2 in both principal directions (b) Multiple stripe analysis results of GLD\#1 and \#2

Subsequently, the collapse fragility functions were obtained considering a lognormal distribution with median collapse intensities and dispersions obtained from the MSA analysis and the simplified relationships developed herein. The comparison is illustrated in Figure 9, where the collapse fragilities for both case study buildings were plotted. Comparing the fragility functions, an excellent match is observed between the two sets in both locations and in the two principal directions of the numerical models. This is true both in terms of the median intensity required to exceed each of these performance limit states and also the level of dispersion. The median collapse intensities reported from the MSA and the associate dispersions pair were respectively $1.58 \mathrm{~g}$ and 0.36 for GLD\#1 and $0.61 \mathrm{~g}$ and 0.39 for GLD\#2. Considering extendedSPO2IDA, the values reported for GLD\#1 in the X-direction are $1.53 \mathrm{~g}$ and 0.29 , whereas for the Y-direction, a median collapse intensity of $1.64 \mathrm{~g}$ and an associated dispersion of 0.31 were estimated. Similarly for GLD\#2, collapse intensities of $0.63 \mathrm{~g}$ and $0.53 \mathrm{~g}$ with dispersion values of 0.20 and 0.23 were predicted for the $\mathrm{X}$ and $\mathrm{Y}$ directions, respectively.

This comparison illustrates the accuracy of the proposed tool to be generally employed for such typologies of different building height and period range across different seismicity types. Moreover, other aspects of the tool not discussed herein but worth mentioning are: (1) the inclusion of the period elongation effect by considering an SDOF system aggregating the backbones of the infill contribution and the frame with the critical storey mechanism formed [21]; (2) the consideration of the sudden rupture of infills on the dynamic stability of the global system. 


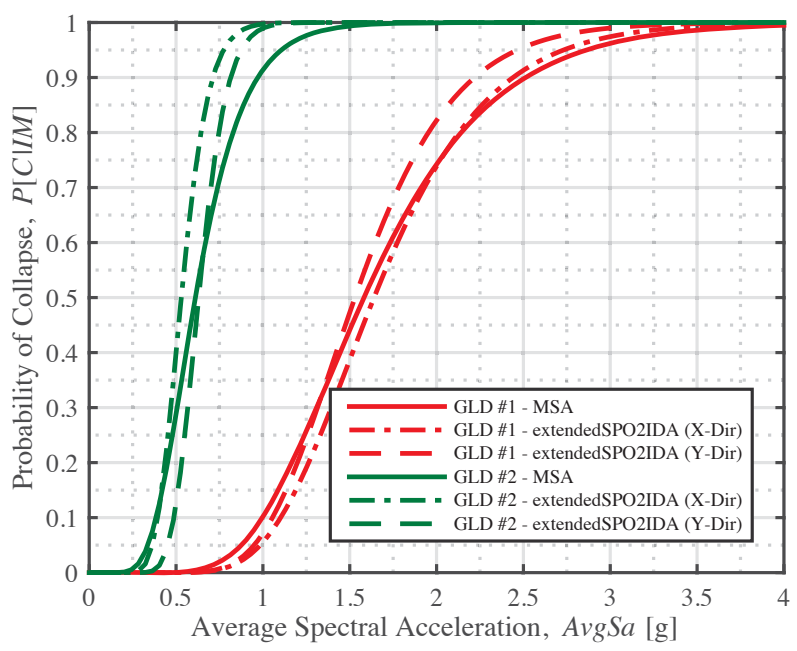

Figure 10: Collapse fragility functions of GLD\#1 and \#2 considering the median collapse intensities and dispersion obtained from MSA and extendedSPO2IDA.

\section{CONCLUSIONS}

The seismic assessment of RC structures with masonry infills is an important issue in modern earthquake engineering considering the prevalence of such typology in the southern European building stock. The characterisation of their behaviour up to global collapse is essential when performing risk-based analyses associated with performance-based earthquake engineering. Non-linear dynamic analyses such as IDA or MSA are computationally expensive in terms of time and effort. To this end, $R-\mu-T$ relationships, incorporating the general response of the structural typology were developed herein. The latter was developed here in terms of $A v g S a$, which demonstrated itself as a more accurate and appropriate IM. From the results of the study developed herein, the following can be noted considering the benefits of the developed tool:

- The consideration of $A v g S a$ as an intensity measure for infilled RC frames is characterised with low dispersions, rendering it a good predictor for collapse estimation.

- The ease of applicability of the tool by simplifies the estimation of collapse capacity and reduces the need for non-linear dynamic analyses by employing eigenvalue and non-linear static procedures as inputs.

- The accuracy of the tool in terms of its ability to predict the median collapse intensity and dispersion for two case study buildings and two different site hazards has been illustrated.

\section{ACKNOWLEDGEMENTS}

The work presented in this paper has been developed within the framework of the project "Dipartimenti di Eccellenza", funded by the Italian Ministry of Education, University and Research at IUSS Pavia. The authors would like to acknowledge the contribution of Arch. Ing. Tereza Nádeníková and Arch. Ing. Barbara Ferma during the conception of the case study buildings presented in this study.

\section{REFERENCES}

[1] Masi A. Seismic vulnerability assessment of gravity load designed R/C frames. Bull Earthq Eng 2003. https://doi.org/10.1023/B:BEEE.0000021426.31223.60.

[2] Repapis C, Zeris CA. Seismic Assessment of Non-conforming Infilled RC Buildings Using IDA 
Procedures. Front Built Environ 2019;4. https://doi.org/10.3389/fbuil.2018.00088.

[3] Decreto R. Norme per la esecuzione delle opere in conglomerato cementizio semplice ed armato. 1939.

[4] O'Reilly GJ, Sullivan TJ. Modeling Techniques for the Seismic Assessment of the Existing Italian RC Frame Structures. J Earthq Eng 2019;23:1262-96. https://doi.org/10.1080/13632469.2017.1360224.

[5] O'Reilly GJ, Sullivan TJ. Probabilistic seismic assessment and retrofit considerations for Italian RC frame buildings. Bull Earthq Eng 2018;16:1447-85. https://doi.org/10.1007/s10518-017-0257-9.

[6] Fardis MN, Calvi GM. Effects of infills on the global response of reinforced concrete frames. 10th Eur. Conf. Earthq. Eng., Balkema, Rotterdam: 1995, p. 2893-2898.

[7] Dolšek M, Fajfar P. The effect of masonry infills on the seismic response of a four-storey reinforced concrete frame — a deterministic assessment. Eng Struct 2008;30:1991-2001. https://doi.org/10.1016/j.engstruct.2008.01.001.

[8] Dolšek M, Fajfar P. The effect of masonry infills on the seismic response of a four storey reinforced concrete frame-a probabilistic assessment. 2008. https://doi.org/10.1016/j.engstruct.2008.04.031.

[9] Dolšek M, Fajfar P. Mathematical modelling of an infilled RC frame structure based on the results of pseudo-dynamic tests. Earthq Eng Struct Dyn 2002;31:1215-30. https://doi.org/10.1002/eqe.154.

[10] Morandi P, Hak S, Magenes G. Performance-based interpretation of in-plane cyclic tests on RC frames with strong masonry infills. Eng Struct 2018. https://doi.org/10.1016/j.engstruct.2017.11.058.

[11] Fardis MN, Negro P, Bousias SN, Colombo A. Seismic design of open-storey infilled RC buildings. J Earthq Eng 1999. https://doi.org/10.1080/13632469909350344.

[12] Vamvatsikos D, Cornell CA. Direct estimation of seismic demand and capacity of multidegree-of-freedom systems through incremental dynamic analysis of single degree of freedom approximation. J Struct Eng 2005;131:589-99. https://doi.org/10.1061/(ASCE)0733-9445(2005)131:4(589).

[13] Baltzopoulos G, Baraschino R, Iervolino I, Vamvatsikos D. SPO2FRAG: software for seismic fragility assessment based on static pushover. Bull Earthq Eng 2017;15:4399-425. https://doi.org/10.1007/s10518017-0145-3.

[14] Dolšek M, Fajfar P. Inelastic spectra for infilled reinforced concrete frames. Earthq Eng Struct Dyn 2004;33:1395-416. https://doi.org/10.1002/eqe.410.

[15] Dolšek M, Fajfar P. Simplified non-linear seismic analysis of infilled reinforced concrete frames. Earthq Eng Struct Dyn 2005. https://doi.org/10.1002/eqe.411.

[16] Guerrini G, Graziotti F, Penna A, Magenes G. Improved evaluation of inelastic displacement demands for short-period masonry structures. Earthq Eng Struct Dyn 2017. https://doi.org/10.1002/eqe.2862.

[17] FEMA. Prestandard and Commentary for the Seismic Rehabilitation of Buildings. Rehabil Requir 2000:1518.

[18] ATC. Improvement of Nonlinear Static Seismic Analysis Procedures. FEMA 440, Fed Emerg Manag Agency, Washingt DC 2005.

[19] Federal Emergency Management Agency P-58-1. Seismic Performance Assessment of Buildings. Fema P-58-1 2012.

[20] Cornell CA, Krawinkler H. Progress and Challenges in Seismic Performance Assessment. PEER Cent News 2000.

[21] Nafeh AMB, O’Reilly GJ, Monteiro R. Simplified seismic assessment of infilled RC frame structures. vol. 18. Springer Netherlands; 2020. https://doi.org/10.1007/s10518-019-00758-2.

[22] Kohrangi M, Kotha SR, Bazzurro P. Ground-motion models for average spectral acceleration in a period range: direct and indirect methods. Bull Earthq Eng 2018;16:45-65. https://doi.org/10.1007/s10518-0170216-5.

[23] Kohrangi M, Bazzurro P, Vamvatsikos D, Spillatura A. Conditional spectrum-based ground motion record selection using average spectral acceleration. Earthq Eng Struct Dyn 2017. https://doi.org/10.1002/eqe.2876.

[24] Kohrangi M, Vamvatsikos D, Bazzurro P. A Record Selection Methodology for Vulnerability Functions Consistent with Regional Seismic Hazard for Classes of Buildings. 16th World Conf Earthq Eng 2017.

[25] Eads L, Miranda E, Lignos DG. Average spectral acceleration as an intensity measure for collapse risk assessment. Earthq Eng Struct Dyn 2015. https://oi.org/10.1002/eqe.2575.

[26] Eads L, Miranda E, Lignos D. Spectral shape metrics and structural collapse potential. Earthq. Eng. Struct. Dyn., 2016. https://doi.org/10.1002/eqe.2739.

[27] O’Reilly GJ, Kohrangi M, Bazzurro P, Monteiro R. Intensity Measures for the Collapse Assessment of Infilled RC Frames. 16th Eur Conf Earthq Eng 2018.

[28] FEMA P695. Quantification of building seismic performance factors. Washington, DC: 2009.

[29] O'Reilly GJ. Limitations of $\mathrm{Sa}(\mathrm{T} 1)$ as an intensity measure when assessing non-ductile infilled RC frame structures. Bull Earthq Eng 2021. https://doi.org/10.1007/s10518-021-01071-7. 
[30] Vamvatsikos D, Cornell CA. Incremental dynamic analysis. Earthq Eng Struct Dyn 2002;31:491-514. https://doi.org/10.1002/eqe.141.

[31] Vamvatsikos D, Bakalis K, Kohrangi M, Pyrza S, Castiglioni CA, Kanyilmaz A, et al. A risk-consistent approach to determine EN1998 behaviour factors for lateral load resisting systems. Soil Dyn Earthq Eng 2020;131. https://doi.org/10.1016/j.soildyn.2019.106008.

[32] ISTAT. Censimento della popolazione e delle abitazioni 2011," Censimento Popolazione Abitazioni 2011.

[33] Pagano M. Teoria degli edifici - Edifici in cemento armato. Edizione L. 1968.

[34] Santarella L. Il cemento armato - Le applicazioni alle costruzioni civili ed industriali. Edizione H. 1968.

[35] McKenna F. OpenSees: A framework for earthquake engineering simulation. Comput Sci Eng 2011. https://doi.org/10.1109/MCSE.2011.66.

[36] Verderame GM, Ricci P, De Risi MT, Del Gaudio C. Experimental Assessment and Numerical Modelling of Conforming and Non-Conforming RC Frames with and without Infills. J Earthq Eng 2019. https://doi.org/10.1080/13632469.2019.1692098.

[37] De Risi MT, Verderame GM. Experimental assessment and numerical modelling of exterior nonconforming beam-column joints with plain bars. Eng Struct 2017. https://doi.org/10.1016/j.engstruct.2017.07.039.

[38] Hak S, Morandi P, Magenes G, Sullivan TJ. Damage control for clay masonry infills in the design of RC frame structures. J Earthq Eng 2012;16:1-35. https://doi.org/10.1080/13632469.2012.670575.

[39] Pagani M, Monelli D, Weatherill G, Danciu L, Crowley H, Silva V, et al. Openquake engine: An open hazard (and risk) software for the global earthquake model. Seismol Res Lett 2014. https://doi.org/10.1785/0220130087.

[40] Mori F, Mendicelli A, Moscatelli M, Romagnoli G, Peronace E, Naso G. A new Vs30 map for Italy based on the seismic microzonation dataset. Eng Geol 2020. https://doi.org/10.1016/j.enggeo.2020.105745.

[41] Baker JW. Conditional Mean Spectrum: Tool for Ground-Motion Selection. J Struct Eng 2011;137:32231. https://doi.org/10.1061/(asce)st.1943-541x.0000215.

[42] Baker JW, Jayaram N. Correlation of spectral acceleration values from NGA ground motion models. Earthq Spectra 2008;24:299-317. https://doi.org/10.1193/1.2857544. 